\title{
The Recombination of Bromouracil-containing Deoxyribonucleic Acid in Salmonella typhimurium Transduction
}

\author{
By B. M. WILKINS* \\ Department of Botany, Queen Mary College, \\ University of London, London, England \\ (Accepted for publication 18 September 1967)
}

SUMMARY

Salmonella typhimurium tolerated the replacement of about $70 \%$ of the thymine in the DNA by 5-bromouracil (BU). In phage PLT-22 transduction, the presence of BU in the donor DNA had no effect on the linkage relationship of two contransduced markers and did not conclusively alter the ratio of complete transductants to abortive transductants. The yield of transductants per plaque-forming unit was more than doubled by the treatment of the donor bacteria and phage with BU. However, more than half of the BU-treated phage particles, detected by electron microscopy, did not form plaques; when the multiplicity of infection was calculated from the titre of physical particles, the frequency of transductants was normal. It is concluded that recombination was not affected by the substantial incorporation of BU into the donor DNA. Treatment of the recipient bacteria with BU slightly modified recombination by decreasing the frequency of transductants by about $40 \%$ and the linkage of the cotransduced markers by about $5 \%$. Because comparable results were not obtained when the donor DNA contained BU, it is suggested that these effects resulted indirectly from the treatment of the recipient bacteria.

\section{INTRODUCTION}

5-Bromouracil (BU) can be incorporated into bacterial DNA in place of thymine (Dunn \& Smith, 1954). No consistent pattern of results has been established in studies investigating the effect of base-analogue substitution on genetic recombination in bacteria. Low concentrations of unifilar and bifilar BU-labeled DNA did not influence the efficiency of transformation in Bacillus subtilis (Szybalski et al. I960; Gimlin et al. 1966) although earlier experiments suggested that the number of recombinants was depressed by treatment (Ephrati-Elizur \& Zamenhof, 1959). In contrast, in Escherichia coli $\mathrm{K} I 2$ conjugation, the treatment of the Hfr parent with BU decreased the amount of the transmitted DNA which was integrated into the recombinant molecule (Folsome, I960; Shchipkov \& Samoylenko, 1966). The present paper, involving the Salmonella typhimurium phage PLT-22 transduction system, was designed to investigate further whether genetic recombination is affected by BU incorporation. The results show that recombination was apparently normal when the donor DNA contained BU but was slightly affected when the recipient bacteria had been treated with BU.

\footnotetext{
* Present address: Radiobiology Laboratories, Yale University School of Medicine, New Haven, Connecticut, U.S.A.
} 


\section{METHODS}

Organisms. The wild type and leu-3araBg mutant (requiring leucine, unable to utilize arabinose) of the LT 2 strain of Salmonella typhimurium were given by Dr P. F. Smith-Keary. The two markers are transduced on the same fragment by the temperate phage PLT-22. The $\operatorname{tryB} 4$ mutant (requiring) tryptophan was obtained from the collection of Dr R. C. Clowes.

Media. Bacteria were grown in basal minimal medium M-26 and enriched M-26 (EM-26) medium, which were based on those of Folsome (1960). M-26 medium contained per litre: $\mathrm{K}_{2} \mathrm{HPO}_{4}, 8.7 \mathrm{~g}$.; $\mathrm{KH}_{2} \mathrm{PO}_{4}, 6.8 \mathrm{~g}$.; $\mathrm{NH}_{4} \mathrm{Cl}, \mathrm{I} \cdot \mathrm{O} \mathrm{g} ; \mathrm{Na}_{2} \mathrm{SO}_{4}$, O.I g. ; $\mathrm{MgCl}_{5}, 0 \cdot 075 \mathrm{~g}$.; $\mathrm{CaCl}_{2}, \mathrm{I} \cdot 5 \mathrm{mg}$.; $\mathrm{FeCl}_{3}, \mathrm{I} \cdot 2 \mathrm{mg}$. ; thiamine, I mg.; glucose, $4 \cdot 0 \mathrm{~g}$. EM-26 contained, per litre, in addition: Ca pantothenate, I mg.; pyridoxine $\mathrm{HCl}$., I mg.; thiamine, I mg.; uracil, I mg.; xanthine, $25 \mathrm{mg}$.; hypoxanthine, $25 \mathrm{mg}$.; Difco vitamin-free Casamino acids, I g. Plating media (Smith-Keary, I960) included minimal medium enriched with I \% (v/v) reconstituted Difco nutrient broth (EMM) and EMB arabinose agar. Enriched arabinose minimal medium (EAMM) had the same composition as EMM except that arabinose was substituted for glucose.

Preparation of bacteria. A sample (0.I ml.) of a culture in medium M-26 was inoculated into $10 \mathrm{ml}$. of treatment medium composed of medium EM-26 supplemented with $100 \mu \mathrm{g} . / \mathrm{ml}$. of aminopterin (to render the bacteria thymine-requiring) + either thymine (Thy) or 5-bromouracil (BU) according to the treatment required. The culture was incubated with aeration for $12 \mathrm{hr}$ at $37^{\circ}$ before use in transduction.

Extent of 5-bromouracil incorporation. The extent of $\mathrm{BU}$ incorporation into the DNA was estimated as follows. The nucleic acids were isolated by the technique of Marmur (I96I). The RNA was removed by hydrolysis with $0.5 \mathrm{~N}-\mathrm{NaOH}$, the DNA was hydrolysed in $72 \%(\mathrm{w} / \mathrm{v})$ perchloric acid and the bases separated by chromatography in isopropanol + hydrochloric acid (Dunn \& Smith, I954, I957; Wyatt, I95I). BU and thymine run as a common spot in this solvent and the amounts of the two bases in the eluate were calculated by the method of Loring (I955) from the extinctions at 260 and $280 \mathrm{~m} \mu$.

Phage stocks and transduction. The procedures were based on those of Smith-Keary (1960). Phages were prepared by the soft-agar technique. The adsorption mixture was composed of equal volumes of a $12 \mathrm{hr}$ Thy- or BU-containing wild type bacterial culture and a phage suspension of $1.5 \times 10^{7}$ plaque-forming units (p.f.u.)/ml. The top layer agar and plate agar were made up of the relevant treatment medium (EM-26+ aminopterin + Thy or BU) with $0.6 \%$ and $\mathrm{I} \cdot 2 \%(\mathrm{w} / \mathrm{v})$ agar, respectively.

For transduction experiments, the recipient leu-39 araB 9 bacteria were washed and resuspended in buffer at $3 \times 10^{9}$ bacteria/ml. Equal volumes of this and a phage suspension containing $3 \times 10^{10}$ p.f.u. $/ \mathrm{ml}$. were mixed, maintained at $37^{\circ}$ for $9 \mathrm{~min}$., and then plated on the selective medium. The number of bacteria surviving phage infection was assayed on EMM+leucine. After $48 \mathrm{hr}$ at $37^{\circ}$, the $\mathrm{Leu}^{+}$and $\mathrm{Ara}^{+}$recombinants, selected on EMM and EAMM+leucine, were characterized for the second phenotype by replica plating on EMB arabinose and unenriched EAMM media, respectively.

Ultraviolet irradiation. The samples in buffer were exposed $35 \mathrm{~cm}$. below a Hanovia I I low-pressure mercury discharge tube. All manipulations were done in subdued lighting to avoid photoreactivation.

Preparation of electron micrographs. Electron micrographs of phage preparations 
were kindly prepared by Dr D. Kay. The particles were negatively stained (Brenner \& Horne, 1959) by mixing $0.7 \mathrm{ml}$. of undiluted phage preparation with an equal volume of $2 \%(\mathrm{w} / \mathrm{v})$ phosphotungstic acid $(\mathrm{pH} 6.2) ; 0 . \mathrm{I} \mathrm{ml}$. of a suspension of polystyrene latex spheres of average diameter $880 \AA$ (Dow Chemical Company) was added and the mixture sprayed on a grid. A series of electron micrographs was then prepared at a magnification of about $\times 45,500$ by using a Philips 200 electron microscope. The latex spheres and phage particles, of head diameter about $470 \AA$ (Bertani, I958), were identified by their relative sizes and the numbers of two components thus determined.

\section{RESULTS}

\section{The extent of 5-bromouracil incorporation}

The base composition of the Thy- and BU-grown leu-39 araB 9 bacteria was estimated as $55^{\circ} 0$ and 54.5 mole \% of guanine + cytosine respectively (each value derived from two experiments). The extent of the replacement of thymine by BU was found to be $70 \%$ in each of two experiments, demonstrating that the base analogue was extensively taken into the bacterial DNA. The growth rate of the bacteria in treatment medium was not affected by BU and the viability of the harvested $\mathrm{I} 2 \mathrm{hr}$ bacteria, estimated by comparing extinctions and colony-forming ability, was normal.

The incorporation of BU-DNA into the transducing particles in high-titre phage stocks, grown on BU-labelled bacteria in media containing BU, was investigated

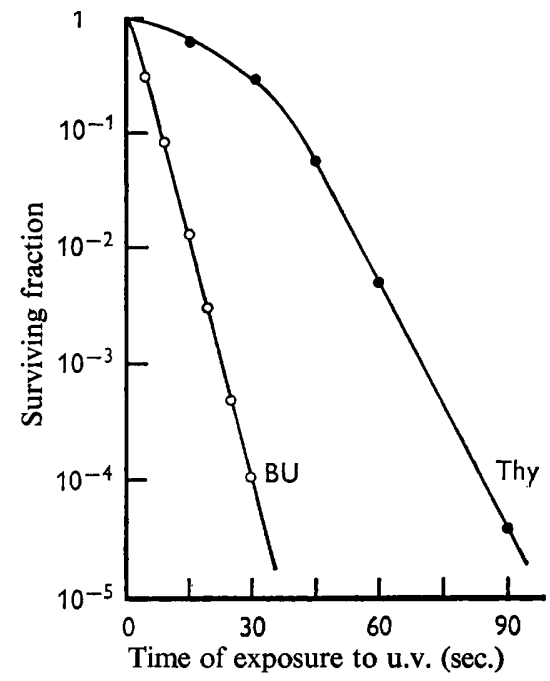

Fig. I

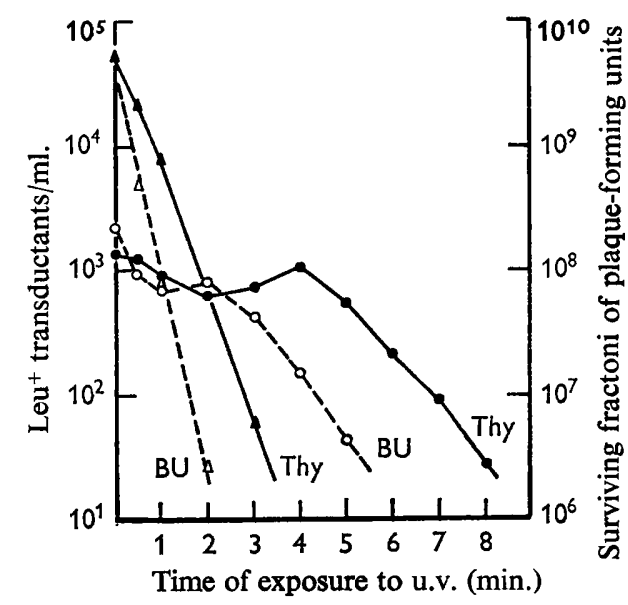

Fig. 2

Fig. I. Survival after ultraviolet irradiation of the colony-forming ability of the leu-39 araBg mutant of Salmonella typhimurium which had been grown in the presence of either BU(O) or thymine (๑). Similar survival curves were obtained for the wild-type strain.

Fig. 2. Inactivation by ultraviolet irradiation of the transduction potential $(0,0)$ and the phage infectivity $(\triangle, \Delta)$ of a thymine (continuous lines) and BU (broken lines) PLT22 phage preparation. The transduction mixture for each assay was composed of $0.4 \mathrm{ml}$. volumes of washed Salmonella typhimurium leu-39 $\mathrm{araBg}$ at $2.5 \times 10^{9} / \mathrm{ml}$. and irradiated phage of initial titre $5 \times 10^{9}$ p.f.u. $/ \mathrm{ml}$. Values on the ordinates refer to $\mathrm{Leu}^{+}$transductions/ml.transduction mixture, and the surviving fraction of p.f.u./ml. phage suspension. 
indirectly. The presence of BU in DNA increases the sensitivity of bacteria to the lethal effects of ultraviolet radiation (Greer, 1960; Fig. I). Thus, the kinetics of u.v.inactivation of the transducing potential of Thy- and BU-treated phage were compared to examine whether the yield of transductants derived from the latter preparation was more effectively reduced by u.v. irradiation.

Each phage preparation was exposed to a series of doses of u.v. radiation. The ability of the phage to form $\mathrm{Leu}^{+}$transductants in the transduction leu-39 araBg (recipient) $\times \pm \pm$ (donor) was determined after each dose; the results are shown in Fig. 2. The more rapid loss of the transduction potential of the BU-treated phage lysate suggests that BU-DNA was included in the transducing particles. Similarly, the increased u.v. sensitivity of the plaque-forming units in this lysate suggests that the analogue was also incorporated into the phage DNA.

\section{The frequency of transductants}

The frequency of $\mathrm{Leu}^{+}$transductants arising in the transduction leu-39 araBg $\times \pm \pm$ was measured when one or both parents had been treated with BU. Although the yield of transductants can be influenced by the addition of small amounts of nutrient broth to the minimal plating medium (Witkin, 1956), the degree of enrichment in EMM, the standard plating medium, was found to be more than sufficient to allow the maximum expression of transductants in all of the experimental classes.

Table 1 . The numbers of $\mathrm{Leu}^{+}$transductants/1 $\mathrm{O}^{8}$ bacteria surviving phage infection arising in the Salmonella typhimurium transduction leu-39araBg $\times \pm \pm$, classed according to: $I$ a. the treatment of the recipient and donor bacteria with thymine or $B U$, and $I b$. the treatment of the recipient bacteria and the multiplicity of infection.

All multiplicities of infection (M.O.I.) are in terms of plaque-forming units per bacterium. Each number is the mean of values obtained in 3 or 4 replicate experiments.

\begin{tabular}{|c|c|c|c|c|c|c|}
\hline & & & & & No of & \\
\hline & Recipient & Donor & no. & S.E. & ments & M.O.I. \\
\hline I $a$ & Thy & Thy & 871 & 161 & 4 & I0 \\
\hline & Thy & BU & 1837 & 214 & 3 & 10 \\
\hline & BU & Thy & 514 & 14 & 4 & 10 \\
\hline & BU & BU & 1110 & 138 & 3 & 10 \\
\hline I $b$ & Thy & Thy & I40I & 93 & 3 & 10 \\
\hline & Thy & Thy & 3112 & 353 & 3 & 27 \\
\hline & BU & Thy & 863 & 135 & 3 & I0 \\
\hline & BU & Thy & 1814 & I47 & 3 & 27 \\
\hline
\end{tabular}

The estimated frequency of transductants for each of the four combinations of treatment, expressed as the number of Leu ${ }^{+}$transductants $/ 10^{8}$ bacteria surviving phage infection, is given in Table $\mathrm{I} a$. Two trends are apparent from the data. BU treatment of the recipient decreased the frequency of transductants by about $40 \%$. However, the frequency was more than doubled when BU-treated phage, grown on BU-containing bacteria, were used in the transduction. There is no evidence of any interaction between treatments in the $\mathrm{BU} \times \mathrm{BU}$ class.

The increase in transductants detected when the donor bacteria and phage had been treated with BU was further examined. The efficiency of the formation of a complete 
transductant can be influenced at two stages: transfer of donor DNA into the recipient bacterium and the following process of its structural integration into the resident DNA. The efficiency of the second stage (genetic recombination) will be reflected in the ratio of complete transductants to abortive transductants (Ozeki, 1956), if these are the alternative fates of the transduced DNA. Thus it might be expected that the increased frequency of complete transductants would be associated with a compensatory decrease in the frequency of abortive transductants if the efficiency of recombination was increased when the donor DNA contained BU. Experiments were made to test this hypothesis.

To facilitate the detection of abortive transductants, the $\operatorname{try} B 4$ (recipient) $\times \pm$ (donor) transduction system was used and the experimental procedure modified. The transduction mixture was composed of $\mathrm{I} \mathrm{ml}$. of an overnight broth culture of the recipient bacteria and $0.1 \mathrm{ml}$. phage suspension to give a multiplicity of infection of 0.7 . Bacteria $\left(4 \times 10^{7}\right)$ were spread on each selective plate of minimal medium $+0.02 \%(w / v)$ Difco vitamin-free Casamino acids. The results are shown in Table 2 and include the numbers of complete $\mathrm{Try}^{+}$transductants $/ 1 \mathrm{IO}^{9}$ phage particles for the two experimental classes involving the Thy- and BU-treated donor DNA and phage. All the complete and abortive transductants on a minimum of two plates in each experiment were scored and the ratio of the two types of transductant derived from the totals. The ratio for the BU-treated donor class was lower than that for the control but this probably reflected the fact that the abortive transductants were less easily identifiable. The total number of complete and abortive transductants $/ 10^{9}$ phage particles, calculated from these two sets of data, was 2734 for the control experiments and 4242 for the class involving the BU-treated donor bacteria. The lack of agreement between these totals suggests that the increased frequency of transductants, detected when the donor bacteria and phage had been grown in BU, primarily resulted from a raised frequency of genetic transfer and not from a greater efficiency of integration of BU-containing transduced DNA.

Table 2. The ratio of complete to abortive Try $y^{+}$transductants and the number of complete Try $y^{+}$transductants $/ 10^{9}$ phage particles arising in the Salmonella typhimurium trasduction tryB $4 \times \pm$, classed according to the treatment of the donor bacteria with thymine or BU (multiplicity of infection: 0.7 )

$\begin{array}{cccc}\begin{array}{c}\text { Recipient } \\ \text { Broth }\end{array} & \begin{array}{c}\text { Donor } \\ \text { Thy }\end{array} & \begin{array}{c}\text { Ratio } \\ \text { complete: abortive } \\ \text { transductants } \\ \text { 199: I21 } \\ (\mathrm{I}: 6 \cdot \mathrm{I})\end{array} & \begin{array}{c}\text { Complete } \\ \text { transductants } / \mathrm{IO}^{\circ} \\ \text { phage particles }\end{array} \\ \text { Broth } & \text { BU } & \begin{array}{c}293: 1470 \\ (1: 5 \cdot 0)\end{array} & 707\end{array}$

A large proportion of the BU-grown phage did not produce plaques on indicator bacteria (see Dunn \& Smith, 1954, 1957). If it be assumed that all the particles could adsorb to the bacteria and inject their DNA, the effective multiplicity of infection in transduction mixtures involving this component should have been calculated from the titre of particles and not that of plaque-forming units. Thus it is proposed that the increased frequency of transductants in the experiments involving BU donor material in Table $\mathrm{I} a$ was caused by the multiplicity of infection being greater than the selected value of 10. 
This hypothesis was examined with Thy- and BU-grown phage lysates prepared under parallel conditions and having titres of $4.3 \times 10^{11}$ and $9.0 \times 10^{10}$ p.f.u. $/ \mathrm{ml}$., respectively. These preparations gave similar numbers of $\mathrm{Leu}^{+}$transductants $/ \mathrm{IO}^{8}$ bacteria surviving infection to those given in Table $1 a$. The counts of particles were determined by electron microscopy. The ratio of particles to latex spheres for the Thy and BU preparations was 37:414 and 32:653, respectively. Therefore, the relative titre of particles in the BU-grown phage lysate was 0.55 that of the control preparation. If the latter had an efficiency of plating of about one, the titre of the BU-treated preparation can be estimated as $2.4 \times 10^{11}$ phage particles $/ \mathrm{ml}$. Thus, it is argued that the effective multiplicity of infection in the BU-treated phage transductions in Table $\mathrm{I} a$ approximated to 27 and not 10 .

When the multiplicity of infection in the two transductions Thy and BU leu-39 araB $9 \times$ Thy \pm \pm was raised from 10 to 27 p.f.u./bacterium, the numbers of $\mathrm{Leu}^{+}$ transductants per $10^{8}$ bacteria surviving infection were increased by about $115 \%$ (Table $\mathrm{I} b$ ). This increase corresponds with the trend established in Table $\mathrm{I} a$, and supports the concept that the treatment of the donor DNA with BU did not effectively alter the efficiency of transduction.

Table 3. The percentage of the selected transductants jointly transduced for the second marker in the Salmonella typhimurium transduction leu-39araB9 \pm \pm , classed according to the treatment of the parental strains with thymine or $B U$

The total for each class was derived from the accumulated data of at least two replicate experiments. Each set of data, tested by a $\chi^{2}$ test, was judged to be homogeneous ( $P$ always greater than $20 \%$ ).

\begin{tabular}{|c|c|c|c|c|c|}
\hline \multicolumn{2}{|c|}{ Treatment } & \multicolumn{2}{|c|}{ Leu $^{+}$selection } & \multicolumn{2}{|c|}{$\mathrm{Ara}^{+}$selection } \\
\hline Recipient & Donor & Total Leu ${ }^{+}$ & $\%++$ & Total Ara ${ }^{+}$ & $\%++$ \\
\hline Thy & Thy & I 375 & $67 \cdot 1$ & I 59 I & $71 \cdot 3$ \\
\hline Thy & BU & 1707 & $67 \cdot 0$ & 1919 & $71 \cdot 0$ \\
\hline BU & Thy & 2576 & $6 \mathrm{I} \cdot 0$ & 2930 & $66 \cdot 4$ \\
\hline $\mathrm{BU}$ & BU & 1622 & $62 \cdot 8$ & 1776 & $65 \cdot 2$ \\
\hline
\end{tabular}

The linkage relationship of cotransduced markers

The effect of BU treatments on recombination was also assessed from the linkage relationship of the two contransduced markers, leu-39 and araB9. The results of these experiments are given in Table 3 and show the total numbers of the selected $\mathrm{Leu}^{+}$and Ara ${ }^{+}$transductants scored, and the percentages of these which were also recombinant for the unselected marker. The various percentages, compared by the normal approximation to the binomial distribution, show that linkage was normal when the transduced donor DNA contained BU, but was slightly decreased by about $5 \%$ when the recipient bacteria had been treated with $\mathrm{BU}(P$ ranging from $\mathrm{I} \cdot \mathrm{I} \%$ to $0.02 \%)$.

\section{DISCUSSION}

Transducing particles containing BU-substituted DNA were prepared by growing phage PLT-22 on BU-treated donor bacteria in media supplemented with BU. The presence of BU in the transduced DNA did not affect such parameters of recombination in transduction as the linkage of cotransduced markers and the ratio of complete 
transductants (recombinants) to abortive transductants (non-integrated DNA). The frequency of transductants per plaque-forming unit was increased by the growth of the donor bacteria and phage in the presence of $\mathrm{BU}$; but when non-viable phage particles detected by electron microscopy, were included in calculations of the multiplicity of infection, the yield of transductants was normal. Thus recombination was not affected when the transduced DNA contained BU. Although the transductions were carried out in media lacking BU, it is unlikely that the transduced fragments were replicated in the recipient bacteria prior to recombination, thus reducing the extent of BU substitution in the exogenotes. The following evidence suggests that the transduced DNA cannot be replicated as a fragment in the recipient bacterium. First, the transduced fragment in an abortive transductant is not integrated and it does not multiply (Ozeki, 1956). Secondly, fragments of bacterial DNA, transferred by conjugation and transformation, cannot multiply in the recipient bacteria if they are not part of a phage or sex factor (Jacob, Brenner \& Cuzin, I963). In generalised transduction by phage P I, a system which resembles that mediated by phage PLT-22, the transduced DNA is not associated with any phage DNA (Ikeda \& Tomizawa, 1965).

BU treatment of the recipient bacteria decreased the frequency of transductants by $40 \%$ and the linkage of two cotransduced markers by about $5 \%$. These effects, which were small and were not matched by comparable effects in transductions involving BU-containing donor DNA, most likely resulted indirectly from treatment which disturbed the physiology of the recipient bacteria in which recombination occurred. It is concluded that Salmonella typhimurium tolerated extensive BU incorporation and that the presence of BU in the DNA did not affect the molecular processes in recombination in phage PLT-22 transduction.

The extent of BU incorporation obtained in these experiments was greater than that achieved in investigations of the effect of $\mathrm{BU}$ on recombination in transformation and conjugation. The normal recombination of BU-containing DNA reported here is consistent with the observations that transformation in Bacillus subtilis was unaffected by the presence of BU in the transforming DNA, when the latter was used at concentrations which did not grossly exceed those required to saturate transformation (Szybalski et al. 1960; Gimlin et al. 1966). Thus conjugation in Escherichia coli $\mathrm{K} 12$ is the only bacterial genetic system in which BU-substituted donor DNA has been found to affect recombination; Folsome (1960) and Shchipkov \& Samoylenko (I966) showed that, following BU treatment of the Hfr, the viable recombinants contained less of the transmitted DNA. Since $E$. coli is susceptible to growth retardation and killing when grown in BU (Dunn \& Smith, 1954) and the genetic studies indicated that BU affected the viability of the Hfr and the kinetics of transfer of markers, the effect of BU on recombination in conjugation may reflect the sensitivity of the $\mathrm{F}^{-}$bacteria to large segments of transmitted BU-containing Hfr DNA rather than a direct effect of the base analogue on the molecular interactions involved in recombination.

I am very grateful to Professor E. A. Bevan for his advice and encouragement during this work and thank $\mathrm{Dr} \mathrm{K}$. A. Stacey for interesting discussions. This investigation was partly supported by a Christopher Welch Scholarship from Oxford University. 


\section{REFERENCES}

Bertani, G. (1958). Lysogeny. Adv. Virus Res. 5, I5I.

BRENNER, S. \& HoRNE, R. W. (I959). A negative staining method for high resolution electron microscopy of viruses. Biochim. biophys. Acta 34, 103.

DUNN, D. B. \& SMITH, J. D. (I954). Incorporation of halogenated pyrimidines into the deoxyribonucleic acids of Bacterium coli and its bacteriophages. Nature, Lond. 174, 305.

DunN, D. B. \& SмrTH, J. D. (1957). Effects of 5-halogenated uracils on the growth of Escherichia coli and their incorporation into deoxyribonucleic acids. Biochem. J. 67, 494.

Ephrati-Elizur, E. \& ZAMENHOF, S. (1959). Incorporation of 5-bromouracil into transforming principle of Bacillus subtilis and its biological effects. Nature, Lond. 184, 472.

FolsOME, C. E. (1960). Effects of 5-bromodesoxyuridine upon gene recombination in Escherichia coli K-I 2. Genetics 45, IIII.

Gimlin, D. M., Hardman, S. D., Kelley, B. N., Butler, G. C. \& Leach, F. R. (I966). Effect of bromouracil-containing deoxyribonucleic acid on Bacillus subtilis. J. Bact. 92, 366.

GrEer, S. (1960). Studies on ultraviolet irradiation of Escherichia coli containing 5-bromouracil in its DNA. J. gen. Microbiol. 22, 618.

IKEDA, H. \& TomiZAWA, J. (1965). Transducing fragments in generalized transduction by phage P I. I. Molecular origin of the fragments. J. molec. Biol. 14, 85.

JACOB, F., BRENNER, S. \& CUZIN, F. (1963). On the regulation of DNA replication in bacteria. Cold Spring Harb. Symp. quant. Biol. 28, 329.

LORING, H. S. (1955). Hydrolysis of nucleic acids and procedures for the direct estimation of purine and pyrimidine fractions by absorption spectrophotometry. In The Nucleic Acids. Ed. by E. Chargaff and J. N. Davidson, vol. I, p. 19I. New York and London: Academic Press.

MARMUR, J. (I96I). A procedure for the isolation of deoxyribonucleic acid from micro-organisms. J. molec. Biol. 3, 208.

Ozeki, H. (1956). Abortive transduction in purine-requiring mutants of Salmonella typhimurium. Genetic studies with bacteria. Publs. Carnegie Instn, no. 61 2, p. 97.

SHCHIPKOV, V. P. \& SAMOYLENKo, L. I. (1966). The effect of 5-bromouracil upon gene recombination in Escherichia coli depending on the amount of thymine it replaces in the DNA of donor cells. Genetika 12, 99. (Orig. in Russian.)

Smith-KeARY, P. F. (1960). A suppressor of leucineless in Salmonella typhimurium. Heredity 14, 6I.

SZYBalski, W., Opara-Kubinska, Z., LoRkiEWICZ, L., EPhrati-Elizur, E. \& ZamenHof, S. (1960). Transforming activity of deoxyribonucleic acid labelled with 5-bromouracil. Nature, Lond. 188, 743.

WITKIN, E. M. (1956). Time, temperature and protein synthesis: a study of ultraviolet-induced mutation in bacteria. Cold Spring Harb. Symp. quant. Biol. 21, 123.

WyatT, G. R. (I95I). The purine and pyrimidine composition of deoxypentose nucleic acids. Biochem. J. 48, 584. 